\title{
Potential risk of transfusion-transmissible infections among blood donors in district Faisalabad of Pakistan
}

\author{
Authors: Ruqqia Rauf and Asma Cheema
}

\section{Background}

In developing countries, blood transfusions have a potential risk of transmitting hepatitis B virus (HBV), hepatitis C virus ( $\mathrm{HCV}$ ), syphilis and malaria to the recipients. ${ }^{1}$ The frequency of these infections among apparently healthy donors may reflect the disease burden in the population. ${ }^{2}$ Thus, the objective of our study was to estimate the potential risk of transfusion-transmissible infections among blood donors in the local population.

\section{Methods}

This was a retrospective study conducted at Madinah Teaching hospital (MTH) blood bank in district Faisalabad from May 2018 to February 2019. Quality-monitored screening of infectious diseases was carried out on using chemiluminescence-based immunoassay (Roche e611). Statistical package of Social Sciences (SPSS) version 22.00 was used to calculate the means and percentages. Logistic regression analysis was performed to identify the potential highrisk donors. A p-value < 0.05 was taken as significant.

\section{Results and discussion}

A total of 6,594 blood donors were included in the study. Mean age of our donors was $29 \pm 7$ years. $6,592(99.97 \%)$ of blood donors were male and $74(1.12 \%)$ were voluntary donors. Most of the blood donations in our set up were being done on replacement basis. In the majority of the cases, family members of the patients donated the blood. Some volunteers also donated the blood. In total, $432(6.55 \%)$ were refused for carrying at least one infection. Of these 432, 214 (3.24\%) were seropositive for HCV, 74 (1.12\%) were seropositive for HBV, $12(0.18 \%)$ were seropositive for HIV, $73(1.10 \%)$ were seropositive for syphilis and $59(0.89 \%)$ were seropositive for malarial parasite. Eleven $(0.16 \%)$ were co-infected with HCV, HBV, HIV and syphilis. Fifteen $(0.22 \%)$ were co-infected with $\mathrm{HBV}$ and $\mathrm{HCV}$. HCV is the most prevalent infection among our local donors followed by HBV, syphilis, HIV and malaria. A study conducted in the southern area of country showed a higher prevalence for $\mathrm{HBV}$ than $\mathrm{HCV}^{3}$ Our study was conducted in the eastern region of the country and showed higher prevalence for $\mathrm{HCV}$. The pattern of infection in our population is quite different from other populations. The other populations show highest prevalence of HBV rather than HCV. ${ }^{4,5}$ The prevalence of HIV is comparatively lower in our population. People belonging to low socioeconomical status were more associated with these infections vs others $(2.56(1.45-4.67)$ vs $2.13(1.12-3.23))$.

\section{Conclusion}

A substantial risk of transmissible infections is present in our population. This demands adhering to the standard operating procedure more meticulously and vigilantly. Community-based studies are required to identify the social risk factors of these infections.

\section{Conflict of interest statement}

None declared.

\section{References}

1 Amiwero CE, Prescott RJ, George OA et al. Seroprevalence of transfusion transmissible infections among blood donors attending the Federal Medical Centre, Bida. IJMBR 2013;1:1-7.

2 Nada HA, Atwa M. Seroprevalence of HBV, HCV, HIV and syphilis markers among blood donors at Suez Canal university hospital blood bank. J Blood Disord Transfus 2013;5:177.

3 Arshad A, Borhany M, Anwar $\mathrm{N}$ et al. Prevalence of transfusion transmissible infections in blood donors of Pakistan. BMC Hematol 2016;16:27.

4 Siraj N, Achila OO, John Issac ] et al. Seroprevalence of transfusiontransmissible infections among blood donors at National Blood Transfusion Service, Eritrea: a seven year retrospective study. BMC Infect Dis 2018;18:264.

5 Biadgo B, Shiferaw E, Woldu B, Alene KA, Melku M. Transfusiontransmissible viral infections among blood donors at the North Gondar district blood bank, northwest Ethiopia: A three year retrospective study. PLOS ONE 2017;12:e0180416. 